\title{
La valoración de la prueba testimonial en el proyecto de Código Procesal Civil. Una tarea inconclusa
}

\author{
Cristián Contreras Rojas*
}

\begin{abstract}
RESUMEN
La presente contribución pretende dar una mirada general al proceso valorativo que debe realizar el juez respecto de la prueba de declaración de testigos. Como se sabe, este medio de prueba siempre ha estado vinculado al temor de que los testigos intenten engañar al juez, de abí que el deber de decir la verdad aparece como la carga principal que se impone a los testigos. De becho, esta opción ha sido tomada claramente por el proyecto de Código Procesal Civil. No obstante, la veracidad de los declarantes es solo uno de los aspectos a los que se debe atender para ponderar acertadamente sus dichos. La memoria y la calidad de los recuerdos que el testigo almacena de los hechos también tienen mucho que decir para la apreciación de este medio de prueba. Por eso, es imprescindible que el legislador procesal recuerde que no puede olvidarse de la memoria.
\end{abstract}

$$
\text { Testigos - valoración - proyecto de Código Procesal Civil }
$$

\section{The assessment of the witness testimony in the Civil Procedural Law Code bill project. An unfinished task}

\begin{abstract}
This contribution intends to give an overview to the assessment process to be performed by the judge on the testimony of witnesses. As is known, this evidence has always been linked to apprehension that witnesses attempt to deceive the judge, hence the main duty of the witness is telling the truth. In fact, this option has clearly been taken by the Civil Procedural Law Code bill project. However, the truthfulness of the witness is just one of the aspects that must be addressed to accurately weigh his words. Memory and quality of the memories also has much to say for assessing this evidence. Therefore, it is essential that the procedural legislature don't forget memory.
\end{abstract}

Witnesses - assessment - Civil Procedural Law Code bill project

* Doctor en Derecho, Universidad de Barcelona. Profesor de Derecho Procesal, Universidad de Talca. Correo electrónico: ccontreras@utalca.cl.

El autor agradece la colaboración y apoyo prestado por Ximena Baeza Barrueto en la preparación de este trabajo.

Artículo recibido el 13 de abril de 2016 y aceptado para su publicación el 1 de marzo de 2017. 


\section{Nociones GeNERALES SOBRE LA PRUEBA EN LA REFORMA PROCESAL CIVIL}

$\mathrm{E}$ 1 proyecto de CPC (en adelante, PCPC) dispone que el juzgador debe presenciar in situ la práctica de las pruebas, en una audiencia de juicio oral, pública y concentrada, luego de ello debe valerse del conocido tridente de elementos de la sana crítica ${ }^{1}$ (principios de la lógica, máximas de la experiencia y conocimientos científicamente afianzados) para fijar racionalmente el mérito de convicción que le corresponde a cada una de las pruebas que se le han hecho llegar ${ }^{2}$. En definitiva, el juez debe construir el razonamiento inferencial que sostiene el fallo sirviéndose de sólidos postulados lógicos, de la experiencia o científicos, todo esto deberá quedar consignado, sin excepción, en la motivación de la decisión.

Sin embargo, y aquí comienzan los inconvenientes, la tarea se complica cuando se piensa en la valoración de pruebas concretas en procesos judiciales determinados, particularmente si se trata de declaraciones testimoniales, tema al que se orienta este trabajo. De hecho, basta un simple análisis abstracto de la actividad valorativa del sentenciador para llegar a la convicción de que a priori esta no se presenta para nada sencilla si tratamos de determinar, por ejemplo, qué quiere decir el legislador cuando se refiere a las máximas de la experiencia como elemento de valoración. Lograr determinar qué es una máxima de experiencia o en qué casos una proposición general cumple con las exigencias para ser calificada como tal ${ }^{3}$, constituyen, de suyo, cuestiones que no admiten absolutismos. He ahí una muestra palpable de la maniobrabilidad que la sana crítica le concede al juez, ventaja que si bien ha llevado a optar consistentemente por ella en nuestras recientes reformas procesales, al mismo tiempo constituye una de las principales dificultades a las que deben hacer frente los llamados a concretar estas cuestiones en la resolución de casos reales.

A mayor abundamiento, las complicaciones para el tribunal no se limitan solo a lo que acabo de mencionar. También es menester tener presente que será usual que la solución de la ecuación valorativa que se le presenta al juzgador no se puede alcanzar únicamente mediante el empleo y la aplicación de conocimientos jurídicos, pues es evidente que en reiterados casos, por no decir en todos, resultará indispensable salir en búsqueda de los saberes contables, tributarios, médicos, ingenieriles, sociológicos o psicológicos, por nombrar algunos, que le permitan no solo acertar en el establecimiento

${ }^{1}$ La noción de sana crítica, como nos recuerda Benfeld, apareció tímidamente por vez primera en el ámbito jurídico procesal nacional en la ley de amnistía número 27 de 1893. Benfeld, J., "Los orígenes del concepto de 'sana crítica", en Revista de Estudios Histórico-Jurídicos, No 35, 2013, p. 570.

${ }^{2}$ La sana crítica constituye un sistema de valoración que hace depender las conclusiones de ciertas formas de construir inferencias que son calificadas como racionales y que el legislador no explicita. Coloma Correa, R., “¿Realmente importa la sana crítica?”, en Revista Chilena de Derecho, Vol. 39, N 3, 2012, p. 763.

3 Acerca de este punto, se ha indicado que la sana crítica busca evitar la errónea aplicación de generalizaciones que carecen de legitimación, son difusas o no poseen un sustento científico. Coloma Correa, R. y Agüero San Juan, C., "Lógica, ciencia y experiencia en la valoración de la prueba", en Revista Chilena de Derecho, Vol. 41, No 2, 2014, p. 675. 
de los hechos, sino de paso comprender a cabalidad todas las aristas del conflicto que debe resolver. Las características de esta empresa hacen que algún autor la haya calificado como intrincada y movediza $a^{4}$, por lo que no debería sorprendernos que los jueces se sientan algo abrumados al momento de enfrentarse a ella ni que, a pesar de sus esfuerzos, los resultados no sean todo lo óptimos que podríamos desear.

Por las razones antedichas, la valoración de las declaraciones testificales no es algo que pueda tomarse a la ligera. A pesar que, de acuerdo con el modelo de sana crítica, el juez de la causa es el llamado a elegir los parámetros de control que utilizará para determinar el mérito de las declaraciones ${ }^{5}$, no es de ninguna manera descabellado pedir al legislador que otorgue algunas orientaciones básicas para llevar a cabo el análisis jurisdiccional de estas pruebas. Con esto se buscaría asegurar en todos los casos la racionalidad de las conclusiones obtenidas -como también, en la medida de lo posible, su acierto-, en el entendido que los lineamientos generales contenidos en la ley sean solo eso, pautas básicas o salvaguardas mínimas de racionalidad y lógica en la valoración judicial de las deposiciones de testigos, que en caso alguno sirvan para constreñir el ejercicio intelectual de apreciación que debe realizar el sentenciador. Querámoslo o no, el juez siempre se sentirá impulsado a buscar en la ley alguna herramienta u orientación para sacar adelante la tarea, guía que no solo debe ser correcta, sino también completa, por lo que el ordenamiento procesal debe ser muy cuidadoso al proporcionar elementos de valoración.

En este aspecto, el PCPC sigue casi al pie de la letra las regulaciones que se han establecido por las reformas procesales previas, particularmente lo contenido en el Código Procesal Penal (arts. 298 y ss.) -replicado en su momento por los artículos 33 y siguientes de la Ley de Tribunales de Familia N ${ }^{\circ} 19.968-$, situación que no es condenable per se si en la mira del legislador procesal está el resguardo de cierta coherencia de la práctica probatoria, independientemente de la sede procesal concreta de que se trate. De hecho, una correspondencia general en el sistema de enjuiciamiento resulta beneficiosa tanto para los operadores jurídicos como para los justiciables. No

\footnotetext{
${ }^{4}$ González Castillo, J., "La fundamentación de las sentencias y la sana crítica", en Revista Chilena de Derecho, Vol. 33, $\mathrm{N}^{\circ} 1,2006$, p. 94.

${ }^{5}$ Dentro de un modelo de valoración de la prueba conforme a las reglas de la sana crítica, el legislador prescinde de realizar valoraciones apriorísticas dejando entregada la labor de apreciación del material probatorio al juzgador del caso concreto. Empero, ello no constituye en ningún caso el otorgamiento de una carta blanca al juez para que decida como mejor le parezca, pues la ausencia de una regulación legal de la valoración no lo exime del deber de cumplir las leyes de la razón, la lógica, la experiencia y el conocimiento de la vida. En este sentido, ver: Prieto-Castro y Ferrándiz, L., Manual de derecho procesal civil, Tomo I, Universidad de Madrid. Facultad de Derecho. Sección de publicaciones e intercambio, Madrid, 1962, p. 294; Gómez Orbaneja, E., Derecho procesal civil, Vol. I, Octava edición, Madrid, 1979, p. 295; Devis Echandía, H., Teoría general de la prueba judicial, Tomo I, Quinta edición, Temis, Bogotá, 2002, p. 314; Alvarado Velloso, A., La prueba judicial: reflexiones críticas sobre la confirmación procesal, Tirant lo Blanch, Valencia, 2006, p. 144. En cuanto a la doctrina nacional puede consultarse: Bordalí, A., Cortez, G. y Palomo, D., Proceso civil: El juicio ordinario de mayor cuantía, procedimiento sumario y tutela cautelar, Segunda edición, Thomson Reuters La Ley, Santiago, 2014, pp. 250 y ss.; Figueroa Yávar, J. y Morgado San Martín, E., Procedimientos civiles e incidentes, LegalPublishing, Santiago, 2013, p. 118; Carocca Pérez, A., Manual de derecho procesal: Los procesos declarativos, Tomo II, LexisNexis, Santiago, 2003, p. 331.
} 
obstante, la reiteración que en este caso se constata implica un desaprovechamiento de la oportunidad que la tramitación de la reforma procesal civil representa para conseguir un upgrade de la regulación normativa que versa respecto de la materia. Básicamente, la reproducción pone de manifiesto que el legislador procesal civil no se ha detenido a revisar si las normas de los órdenes procesales vigentes prevén de forma completa y adecuada las particularidades de la prueba de declaración de testigos, más en concreto, si existe o no un análisis serio tanto de lo que las declaraciones testimoniales pueden dar de sí como de los elementos que deben considerarse para determinar acertadamente su nivel de credibilidad y convicción ${ }^{6}$.

Considere el lector lo siguiente: el PCPC en su artículo 310 señala que toda persona que ha sido llamada como testigo debe declarar la verdad sobre lo que se le preguntare. Más allá de lo pretenciosa que puede parecer una norma procesal de este tipo, resulta pertinente preguntarse: ¿es posible exigir a los testigos que declaren la verdad de los hechos? Si la respuesta fuere afirmativa, ¿contamos con los mecanismos racionales y suficientes para verificar el cumplimiento de este deber? Y por otra parte, ¿basta con detenerse a analizar si el testigo ha dicho la verdad para calibrar adecuadamente el mérito de su declaración? Como veremos, el legislador al referirse a los aspectos de la declaración se ha centrado -y se sigue centrando- únicamente en su nivel de veracidad, desatendiendo completamente a la memoria del declarante y su funcionamiento, que claramente tiene algo que decir (rectius, que recordar) concerniente a la forma en que acaecieron los hechos acerca de los que debe ilustrar al tribunal. De ahí que me anime a sostener que cualquier valoración de las declaraciones de testigos que se realice de acuerdo con las actuales normas se tratará de un ejercicio incompleto. Vamos a ver cuáles son las piezas faltantes.

\section{FACTORES GENERALES DE VALORACIÓN} DE LAS DECLARACIONES TESTIFICALES

Como se ha venido indicando, el PCPC establece que en materia de valoración de declaraciones testificales el juez debe operar de acuerdo con la sana crítica, partiendo de la base que la lógica, la experiencia y la ciencia son capaces de proporcionar fundamentos sólidos para la construcción de inferencias racionales y objetivas sobre el mérito de convicción de lo que ha sido relatado por el testigo. Expuesto de otra forma, desde el momento en que el legislador procesal opta por un modelo de sana crítica en que se establecen expresamente los elementos que deben ser empleados para calibrar los dichos de los declarantes, se acepta que la lógica, la experiencia o la ciencia son capaces de proveer un conocimiento válido que, contrastado con el material fáctico que obra en

${ }^{6}$ Aspectos que tampoco han sido tratados por la doctrina nacional. A modo ejemplar: Caroca, cit., p. 258; Bordalí, Cortez y Palomo, cit., p. 345; Rodríguez Papic, I., Procedimiento civil: Juicio ordinario de mayor cuantía, Séptima Edición, Editorial Jurídica de Chile, Santiago, p. 191. 
autos, permitirá obtener conclusiones acertadas acerca de cómo han acaecido realmente los hechos de la causa ${ }^{7}$.

Teniendo presente lo anterior, ¿cuál es la fuente de la que debemos extraer los conocimientos que nos permitan elaborar inferencias correctas a partir del resultado de la prueba testimonial? Esta cuestión solo puede resolverse adecuadamente atendiendo a los postulados de la psicología del testimonio ${ }^{8}$, ciencia que se ha dedicado a estudiar todos los factores que influyen en la calidad de los relatos fácticos que pueden ser proporcionados por los sujetos ${ }^{9}$. Los resultados de las investigaciones que han sido llevadas a cabo en esta área han ayudado a comprender los factores que afectan tanto a la veracidad de las declaraciones como a su exactitud, siendo estos los dos aspectos que inexcusablemente deben ser considerados en toda valoración de los relatos que tenga pretensiones de sensatez y certeza. Esto se debe a que claramente la calidad del contenido de toda declaración es determinada no solo por su veracidad sino también por ciertas variables personales y contextuales, como la complejidad del evento y las habilidades cognitivas del testigo ${ }^{10}$. De esta forma, por una parte los estudios de la psicología de la memoria han permitido conocer cómo funciona el recuerdo, las etapas por las que atraviesa y los distintos factores que influyen en su calidad ${ }^{11}$. A ello se deben agregar, como necesario complemento, los avances en materia de evaluación del nivel de credibilidad de los relatos y la detección de la mentira, ámbito en que se ha tendido a la consecución de sistemas que permitan asegurar racionalidad, justificación y control intersubjetivo de los resultados, buscando dejar de lado toda apreciación voluntarista y antojadiza que pueda emitirse acerca de la veracidad de los declarantes ${ }^{12}$.

\footnotetext{
${ }^{7}$ Aunque este conocimiento válido también deberá ser sometido a verificación, especialmente el obtenido desde las máximas de experiencia. Taruffo, M., Simplemente la verdad: el juez y la construcción de los hechos, traducción de Daniela Accatino Scagliotti, Marcial Pons, Madrid, 2010, p. 75. También: Montero Aroca, J., La prueba en el proceso civil, Séptima edición, Civitas Thomson Reuters, Cizur Menor, 2012, p. 617.

${ }^{8}$ Aunque no todos estén de acuerdo en que los postulados de la psicología del testimonio permiten conseguir conclusiones sólidas. En efecto, se ha indicado que la psicología de la declaración, incluso sometiendo el testimonio al análisis más riguroso, solo puede aportar una evaluación probabilística acerca de su veracidad, dejando un margen de inseguridad demasiado amplio. Sancinetti, M., "Testimonio único y principio de la duda”, en InDret, $\mathrm{N}^{\circ} 3,2013$, p. 15.

${ }^{9}$ Ibabe Erostarbe, I., Psicología del testimonio, Erein, Donostia, 2000, p. 10.

${ }^{10}$ Volbert, R. y Steller, M., "Is this testimony truthful, fabricated, or based on false memory? Credibility assessment 25 years after Steller and Köhnken (1989)", en European Psychologist, Vol. 19, N 3, 2014, p. 211.

${ }^{11}$ Sobre este tema, basta con examinar el excelente trabajo que da inicio al estadio actual de desarrollo de la psicología del testimonio: Loftus, E., Eyewitness testimony, Harvard University Press, Cambridge, 1979. Para una versión actualizada: Loftus, E., Doyle, J. y Dysart, J., Eyewitness testimony: civil and criminal, Quinta edición, LexisNexis, New Providence, 2013.

${ }^{12}$ Con este propósito se han desarrollado distintas técnicas y metodologías que han intentado evaluar el contenido verbal de las declaraciones, como el Análisis de la realidad de las declaraciones o el Análisis del contenido basado en criterios. Ver: Undeutsch, U., "Statement reality analysis", en Trankell, A. (editor), Reconstructing the past: the role of psychologists in criminal trials, p. A. Norstedt, Estocolomo, 1982, pp. $27 \mathrm{y}$ ss; Steller, M., "Recent developments in statement analysis", en Yuille, J. C. (editor), Credibility assessment, Springer, Deventer, Vol. 47, 1989, pp. 135 y ss.; Steller, M. y Köhnken, G., "Análisis de declaraciones basado en criterios”, en Raskin, D. (editor), Métodos psicológicos en la investigación y pruebas criminales, Springer,
} 
En consecuencia, es claro que la actividad valorativa del sentenciador respecto de las declaraciones testificales debe detenerse a analizar tanto el nivel de veracidad como el de exactitud de las deposiciones, llegando a conclusiones que se refieran por separado a ambas cuestiones y que se plasmen en el texto de la sentencia del caso.

Lo anterior queda de manifiesto si se considera lo siguiente: debemos suponer que todo testigo que es llamado a deponer ante el tribunal tiene conocimiento de los hechos objeto del juicio, pues de lo contrario la parte no lo habría propuesto para que declarara en apoyo de su versión fáctica. En este sentido, hay que tener presente también que el deponente guarda en su memoria una versión de los sucesos, sea porque los ha presenciado directamente o porque ha oído un relato de ellos. Dejando de lado para este ejercicio al testimonio de oídas -que debido a sus características particulares no será abordado en este trabajo-, pensemos que en primer término el ejercicio de juzgador deberá comenzar por determinar si el litigante ha sido honesto en sus declaraciones, vale decir, si ha tenido o no la intención de engañarlo por medio de la provisión consciente de un relato falso o alterado de los sucesos ${ }^{13}$. Si el tribunal llega a la convicción que el deponente ha mentido, necesariamente la declaración será diferente al recuerdo que se encuentra almacenado en la memoria del sujeto, razón por la que es posible concluir que carece de toda credibilidad -o que en el mejor de los casos solo debe asignársele un nivel muy bajo en la escala de veracidad-, pues por esta sola circunstancia sus dichos difieren de la real ocurrencia de los hechos. En esa situación resultará inútil entrar al examen del nivel de precisión de la memoria del declarante, pues esto en nada puede alterar la conclusión inicial sobre el mérito probatorio de la declaración obtenida a partir del juicio de veracidad.

Por su parte, si del análisis de lo expuesto el juez concluye que el declarante ha sido veraz, necesariamente se deberá pasar luego al establecimiento del nivel de exactitud de lo expuesto. De esta forma, las conclusiones conseguidas en la primera etapa de análisis -que llevan al evaluador a creer que los eventos ocurrieron tal como los relata el testigo- pueden verse refrendadas y fortalecidas por el examen sobre la precisión de la declaración, en el caso que el juez llegue a la convicción que el sujeto ha expuesto un recuerdo fiel de los hechos. Empero, si el relato contiene elementos que permiten concluir que estamos frente a una huella de memoria que se ha visto debilitada o alterada en sus aspectos sustanciales, o que lisa y llanamente ha sido implantada con posterioridad a los sucesos, el juzgador tendrá que restarle todo peso probatorio a la narración ${ }^{14}$.

En suma, junto con el elemento volitivo que determina la honestidad de la deposición, entra en escena la capacidad del sujeto para formar, almacenar y transmitir un relato exacto de lo ocurrido, de manera que el sentenciador tiene la misión de dilucidar si lo expuesto se ajusta a los hechos ocurridos en un nivel que al menos supere el umbral

Bilbao, 1994, pp. 189 y ss.; Vrij, A., "Criteria-based content analysis: a qualitative review of the first 37 studies”, en Psychology, Public Policy, and Law, Vol. 11, No 1, 2005, pp. 3 y ss.

${ }^{13}$ Vrij, A., Detecting lies and deceit: Pitfalls and opportunities, Segunda edición, Wiley, Chichester, 2008, p. 14 .

${ }^{14}$ Carnelutti, F., La prueba civil, traducción de Niceto Alcalá-Zamora y Castillo, Segunda edición, Ediciones Depalma, Buenos Aires, 1982, p. 119. 
mínimo necesario para que esta prueba pueda ser empleada como material de fijación del componente fáctico de la litis. Esto porque, como han expresado los psicólogos del testimonio, la memoria humana no registra los hechos como una cámara de video ${ }^{15}$, sino que solo graba una parte de ellos - particularmente, la que interesa al observador-, y además el recuerdo que guardamos lleva ínsita la interpretación personal del hecho. Por ello, la mejor forma de saber si el relato es exacto sería comparar lo que el testigo ha relatado con otro registro del hecho mismo (por ejemplo audiovisual). Sin embargo, en la mayoría de las situaciones no se cuenta con una grabación fidedigna de lo ocurrido, circunstancia que precisamente justifica la presentación de prueba testimonial en los procesos judiciales $^{16}$.

\section{Acerca del control de veracidad del relato}

El peligro latente de que el testigo no sea más que un embustero que proporciona un relato inventado con el objetivo de beneficiar al litigante que lo presenta en el juicio -o, por el contrario, perjudicar a la contraparte- ha llevado desde siempre a mirar a priori con recelo el otorgamiento de un grado de convicción a este medio de prueba. El hecho que ya desde las primeras leyes de las que se tiene registro se haya requerido de al menos la declaración conteste de dos testigos para así concederle pleno valor a sus dichos ${ }^{17}$, es una manifestación concreta de la urgencia por encontrar una fórmula que permita otorgar mayores garantías de veracidad a lo expuesto por el declarante, y que quizás se ideó teniendo en cuenta que existen menores probabilidades de que dos testigos mientan en un mismo proceso a que solo lo haga uno de ellos ${ }^{18}$. De ahí que la concurrencia de declaraciones se haya estimado como una especie de prueba de la blancura de sinceridad. Pero dejando de lado las objeciones lógicas evidentes que se pueden plantear a esta regla, es innegable que aunque han pasado miles de años desde su primera consagración expresa, una norma análoga se encuentra aún vigente en nuestro sistema procesal civil, y si bien no se ha estimado oportuna su inclusión en el PCPC -debido al cambio de modelo en lo que respecta a la valoración probatoria-, es patente que el legislador de ayer y hoy conserva una preocupación primordial por evitar que el testigo engañe al tribunal del proceso.

En esta perspectiva, en nuestro actual proceso civil escrito, donde una valoración legal o tarifada se ve aderezada por la ausencia del juez durante el acto de la declaración, el legislador apriorísticamente ha establecido que los dichos de una sola persona no pueden ser considerados per se una versión suficiente de los sucesos, pues este efecto se

${ }^{15}$ Manzanero Puebla, A., Memoria de testigos, Ediciones Pirámide, Madrid, 2010, p. 23.

${ }^{16}$ En todo caso, la declaración testimonial también posee sus ventajas en relación con los demás medios de prueba, toda vez que destaca porque el declarante puede adaptarse a las exigencias del averiguador y cuidar en mayor medida aquellas partes de la representación que al averiguador interesen, detallando, aclarando, repitiendo, Carnelutti, cit., p. 121.

${ }^{17}$ Ver: Nieva Fenoll, J., La valoración de la prueba, Marcial Pons, Madrid, 2010, p. 47.

${ }^{18}$ Contreras Rojas, C., La valoración de la prueba de interrogatorio, Marcial Pons, Madrid, 2015, p. 216. 
logra únicamente cuando una declaración equivalente es proporcionada por dos o más sujetos. De hecho, esto puede parecer un resguardo coherente de parte del ordenamiento jurídico si se tiene en cuenta que, por un lado, los seres humanos se sienten recurrentemente tentados a mentir o pueden ser influenciados para hacerlo, y por otro, que en su momento se desconfiaba de las capacidades efectivas del sentenciador para asignar correctamente el mérito a las pruebas disponibles ${ }^{19}$, mientras que ahora nos enfrentamos a un juez que no está presente en el acto de la declaración, lo que le impediría controlar o percibir los elementos que develan la presencia de la mentira.

Sea como fuere, el sistema procesal pone de manifiesto su intención de que el testigo se abstenga de suministrar algún contenido mendaz en su declaración y que al mismo tiempo el juez centre toda su atención en detectar cualquier atisbo de mentira, para así privar de valor al relato que incurra en ella. No obstante, nada dice respecto de cómo debe realizarse esta evaluación de credibilidad, aspecto que se torna crítico tratándose de una valoración conforme a la sana crítica del sentenciador. Es razonable que en un modelo civil oral impregnado del sistema de la sana crítica, como el que se quiere establecer por el PCPC, se permita que el juez de la causa asigne libre, pero justificadamente, el valor de convicción de un solo relato ${ }^{20}$, pues su presencia en el desarrollo del acto probatorio le posibilita la obtención de los insumos propicios para apreciar adecuadamente el mérito de lo que se ha dicho, pero siempre habrá que tener sumo cuidado en la elección de los elementos que son sopesados para medir la honestidad del declarante.

La psicología del testimonio ha dejado en claro que el acto de mentir tiene como correlato la generación de una mayor carga cognitiva para el sujeto ${ }^{21}$, lo que puede quedar de manifiesto en la conducta del declarante ${ }^{22}$ o en el contenido de sus dichos ${ }^{23}$ (dependiendo de la corriente que se siga al efecto). En este sentido, se apunta que la persona que intencionadamente relata una historia que se aparta del recuerdo que tiene de los acontecimientos - sea que se trate de una versión totalmente inventada porque no ha presenciado los hechos, sea porque agrega, omite o altera aspectos de lo sucedido- no solo tiene la urgencia por ajustarse al guion que ha fabricado y estudiado, sino que al

19 Taruffo, M., La prueba, traducción de Laura Manríquez y Jordi Ferrer Beltrán, Marcial Pons, Madrid, 2008, p. 134.

${ }^{20}$ Desde luego, el sentenciador tiene el deber de explicitar la regla o máxima de la que se ha servido para conferir o restar valor a lo declarado por el testigo. En este sentido, se ha afirmado: Para que una decisión se base solamente en el relato de una sola persona, el juez debe dar las razones de por qué tales dichos no pueden ser falsos. Sancinetti, cit., p. 11. También: Abel Lluch, X., "Configuración de las reglas de la sana crítica en la Ley 1/2000, de Enjuiciamiento Civil”, en Revista Vasca de Derecho Procesal y Arbitraje, Vol. XXV, N 2, 2013, p. 159; Coloma, cit., p. 765.

${ }^{21}$ Zuckerman, M., Depaulo, B. y Rosenthal, R., "Verbal and nonverbal communication of deception", en Advances in Experimental Social Psychology, Vol. 14, 1981, p. 7. También: Vrij, Detecting lies, cit., p. 40.

${ }^{22}$ Ekman, P., Cómo detectar mentiras: una guía para utilizar en el trabajo, la política y la pareja, Paidós, Barcelona, 2009, p. 43.

23 Godoy-Cervera, V. e Higueras, L., "El análisis de contenido basado en criterios (CBCA) en la evaluación de la credibilidad del testimonio", en Papeles del Psicólogo, Vol. 26, 2005, p. 92; Sporer, S., "The less travelled road to truth: verbal cues in deception detection in accounts of fabricated and self-experienced events", en Applied Cognitive Psychology, Vol. 11, No 5, 1997, p. 374. 
mismo tiempo, para tener éxito en su embuste, debe poner atención en que el relato modificado calce con lo que los receptores de la mentira saben o pueden averiguar acerca de los mismos sucesos. En este aspecto, para el declarante mendaz es relevante también tener en cuenta la versión de los hechos que es suministrada al sentenciador por fuentes de prueba diversas, sobre todo si ellas corresponden a la información entregada por otros declarantes, caso en el que el testigo deberá esforzarse por parecer más creíble en todos los aspectos lingüísticos y conductuales de su declaración -debido al valor que suele asignársele a ambos- ${ }^{24}$.

El aumento de la carga cognitiva puede llevar a que el testigo sea incapaz de ocultar las mentiras que ha incluido en su declaración, de modo que resulta conveniente poner a prueba la aptitud del declarante para soportar dicha carga, solicitándole, por ejemplo, la contextualización de los hechos relatados o la alteración del orden secuencial de la narración. Así, se ha destacado que puede bastar con requerir al declarante que detalle los acontecimientos en un orden temporal inverso al que ocurrieron -comenzando desde el final o desde un punto intermedio-, para de esta forma conseguir la ruptura del esquema que había preparado y ensayado ${ }^{25}$. De esta manera, si se trata de una narración inventada y el testigo no ha previsto la necesidad de alterar el guion de los sucesos, es factible que queden en evidencia lagunas de información, inconsistencias o contradicciones en sus dichos, los que pueden servir de elementos para presumir una falta de honestidad de su parte ${ }^{26}$. Lo mismo ocurre si se pide al declarante que contextualice los sucesos, pues su incapacidad de hacerlo puede ser señal de un relato fabricado. En este aspecto, es esperable que aquella persona que ha presenciado los hechos sea capaz de describir claramente todos los elementos espacio-temporales que los acompañan, como asimismo proporcionar información respecto del estado emocional y psicológico que experimentó en el momento de presenciarlos ${ }^{27}$.

En todo caso, no debe perderse de vista que el objetivo final es que la mentira se refleje en las información verbal que proporciona el declarante, pues desde la psicología del testimonio se ha resaltado que el objeto de análisis, con miras a la determinación de la veracidad de lo expuesto, debe ser el contenido de la declaración, no la persona

${ }^{24}$ Además, en virtud de que los mentirosos tienen pleno conocimiento acerca de la falta total o parcial de fidelidad de lo que cuentan, estarán menos dispuestos a dar por hecho que el oyente creerá la versión fáctica que le proporcionan, de modo que tenderán a vigilar las reacciones de su interlocutor con el fin de averiguar si su mentira está o no siendo aceptada. Vrij, A., "Interviewing to detect deception", en European Psychologist, Vol. 19, N 3, 2014, p. 186.

${ }^{25}$ Arce, R. y Fariña, F., "Peritación psicológica de la credibilidad del testimonio, la huella psíquica y la simulación: el Sistema de Evaluación Global (SEG)”, en Papeles del Psicólogo, No 92, 2005, p. 61.

${ }^{26}$ Diges Junco, M. y Alonso-Quecuty, M., Psicología forense experimental, Promolibro, Valencia, 1993, p. 94.

${ }^{27}$ Nieva, cit., p. 226. Por otra parte, es menester agregar que siempre es previsible que el falso declarante prepare sus respuestas teniendo en vista las posibles preguntas que le serán formuladas. De ahí que los requerimientos adicionales acerca de elementos medulares o contextuales de los sucesos pueden servir como herramientas para demostrar la carencia de honestidad del declarante, más aún si los temas indagados tienen relación con cuestiones centrales del evento a los que el declarante rehúye referirse o que menciona mediante respuestas que no son coherentes con lo afirmado previamente. Vrij, Interviewing, cit., p. 187. 
del testigo ${ }^{28}$. De esta manera, se debe atender a lo que dice el declarante, o sea, a las palabras que van configurando su narración, absteniéndose de toda consideración por la forma en que lo dice. Con ello, se deja de lado cualquier intento por detectar si el testigo miente o dice la verdad a partir de sus manifestaciones fisiológicas de ansiedad, el comportamiento que exhibe durante la declaración (movimientos corporales, gestos, dirección de la mirada, etc.) o las señales paraverbales que emite durante la práctica de la prueba (tono de voz, silencios, cadencia, entre otros), que si bien intuitivamente pueden parecer fiables en este afán, no sirven sino para alcanzar resultados subjetivos y arbitrarios ${ }^{29}$. Así, asumiendo que en el estadio actual de desarrollo científico aún no contamos con un indicador completamente fiable de mendacidad, se ha estimado que sería aceptable determinar el nivel de veracidad de una declaración mediante el análisis de su contenido verbal a partir de ciertos criterios que permitirían distinguir entre relatos falsos y verdaderos, asumiendo que entre ambos existen diferencias detectables ${ }^{30}$. Con esto, al menos, es posible alcanzar resultados que pueden ser controlados intersubjetivamente al sustentarse en elementos objetivos (las palabras que componen la narración) ${ }^{31}$.

\section{Sobre la memoria y la exactitud de los recuerdos}

La percepción directa de un hecho y su registro en el almacén de memoria es solo la primera de las tres etapas por las que atraviesa el recuerdo ${ }^{32}$, existiendo elementos que intervienen en cada una de ellas y que pueden afectar la calidad de lo que recorda$\operatorname{mos}^{33}$. Así, en el momento en que el sentenciador evalúa lo que un testigo ha relatado, debe poner atención a las condiciones en que se han llevado a cabo las tres etapas, para de esa forma determinar los factores que han intervenido en el período que va entre la formación de la huella de memoria y la declaración judicial, así como el nivel en que ellos han podido afectar positiva o negativamente al recuerdo.

\footnotetext{
${ }^{28}$ Manzanero Puebla, A., Psicología del testimonio, Ediciones Pirámide, Madrid, 2008, p. 177.

${ }^{29}$ En este aspecto, se ha remarcado que los intentos por detectar la presencia de un declarante embustero han transitado desde los ensayos por establecer las alteraciones fisiológicas periféricas provocadas por el aumento del nivel de ansiedad que se asocia a la mentira -mediante la utilización del polígrafo-, al examen de las perturbaciones cerebrales que podrían ser apreciadas por medio de neuroimágenes. El problema de estas técnicas, en todo caso, sigue residiendo en la imposibilidad de establecer una correspondencia cierta entre dichas señales y el engaño, que resulte operativa en todas y cada una de las personas examinadas. Gamer, M., "Mind reading using neuroimaging. Is this the future of deception detection?", en European Psychologist, Vol. 19, $\mathrm{N}^{\mathrm{o}} 3$, 2014, p. 173. Una descripción detallada de los resultados obtenidos con el empleo de estas técnicas puede encontrarse en: Vrij, Detecting lies, cit., pp. 293 y ss.

${ }^{30}$ Para un análisis pormenorizado de estas técnicas y metodologías, ver referencias indicadas supra, nota 12 .

${ }^{31}$ Manzanero, Memoria de testigos, cit., p. 84. En el mismo sentido: Diges y Alonso-Quecuty, cit., p. 113.

32 Manzanero, Psicología del testimonio, cit. p. 38.

${ }^{33}$ En este sentido se ha afirmado que cada una de las variables que pueden afectar positiva o negativamente la precisión de un testimonio pueden utilizarse como indicadores de la probabilidad de que se hayan cometido errores involuntarios por parte del declarante. Köhnken, G., Manzanero, A., y Scott, M. T., "Análisis de la validez de las declaraciones: mitos y limitaciones”, en Anuario de Psicología Jurídica, Vol. 25, 2015, p. 15.
} 
No basta con que la codificación del recuerdo (formación de la buella o trazo de memoria) se realice en condiciones óptimas para que la declaración del testigo honesto se ajuste a lo que efectivamente ocurrió, pues el recuerdo puede haber sido deformado posteriormente mientras permanecía alojado en la memoria de largo plazo o durante el acto mismo de la deposición. Lo que sí es claro es que estos tres momentos conforman una cadena de tres eslabones donde las deficiencias de uno de ellos impactará directa y necesariamente en el recuerdo que se recuperará en definitiva, por lo que debe considerarse que el correcto registro de los acontecimientos constituye un requisito necesario, mas no suficiente, de una buena declaración.

\subsection{Factores que intervienen en la codificación del recuerdo}

Se ha indicado que en el instante en que el sujeto presencia los sucesos y los incorpora en su memoria, vale decir, se produce la codificación de los hechos -el primero de los tres momentos en que funciona la memoria, junto con la retención y la recuperación ${ }^{34}$ será capaz de fijar un recuerdo de mejor o peor calidad o intensidad dependiendo de la concurrencia de algunos elementos que se vinculan con las características propias del acontecimiento o con sus condiciones personales ${ }^{35}$. En el primer caso, se trata de factores concomitantes con el hecho a recordar y que reducen la habilidad de cualquier testigo para referirse a él con precisión (independientemente de la persona concreta que lo ha presenciado). Por su parte, las condiciones personales del testigo se refieren tanto a su condición física, mental o psicológica, como a su nivel sociocultural y educacional, todo lo que constituye un cúmulo de factores que redundan en su idoneidad para percibir, interpretar, almacenar y dar cuenta de los acontecimientos.

En este sentido, en lo que respecta a las propiedades del suceso, se ha señalado, por ejemplo, que su duración será vital para mejorar la habilidad del individuo para dar cuenta posterior de él, ya que la cantidad de tiempo para apreciar el hecho irá en directa relación con la precisión de su percepción y recuerdo ${ }^{36}$. Lo mismo puede decirse respecto de las condiciones de iluminación ${ }^{37}$ y de sonido, ya que cuando ellas son de

${ }^{34}$ Las dos primeras fuera del control del juez. Wells, G., "Applied eyewitness-testimony research: system variables and estimator variables”, en Journal of Personality and Social Psychology, Vol. 36, N 12 , 1978 , p. 1548.

35 Manzanero, Memoria de testigos, cit., pp. 23 y ss.

36 Loftus, E., Greene, E. y Doyle, J., "La psicología del testimonio del testigo presencial", en Raskin, D. (editor), Métodos psicológicos en la investigación y pruebas criminales, traducción de Susana Gorbeña Etxebarría, Desclée de Brouwer, Bilbao, 1994, p. 25. Aunque la tarea de determinar la duración del hecho puede presentarse como una labor complicada en situaciones de estrés, que usualmente lleva al observador a exagerar la extensión temporal del evento. Loftus, E., Schooler, J., Boone, S. y Kline, D., "Time went by so slowly: overestimation of event duration by males and females", en Applied Cognitive Psychology, Vol. 1, $\mathrm{N}^{\circ} 1,1987$, p. 3.

${ }^{37}$ En este aspecto, siempre viene bien recordar a Gorphe: "Una escena mal iluminada es necesariamente mal vista; la percepción en ella es incompleta; el recuerdo será esquemático y lacunario". Gorphe, F., La crítica del testimonio, traducción de Mariano Ruiz-Funes, Sexta edición, Reus, Madrid, 1980, p. 238. 
mayor calidad, más posibilidades habrán de que el registro de los sucesos sea realizado de mejor manera, pues son evidentes las limitaciones que el género humano posee para captar ciertas frecuencias de sonido o para ver en la oscuridad ${ }^{38}$. Además, algunos detalles de los acontecimientos son más sobresalientes que otros, de modo que es esperable que aquellos aspectos destacados, como la utilización de una vestimenta fuera de lo común por parte de alguno de los intervinientes, el porte de algún símbolo distintivo, un tatuaje en el rostro o la utilización de un arma, captará mayormente la atención de los observadores, por lo que aumentarán las posibilidades de ser recordados ${ }^{39}$.

Ahora bien, no basta con que objetivamente un evento se desarrolle en condiciones ideales, sino que es necesario que ello vaya acompañado de un observador que se encuentra dotado de las capacidades cognitivas y sensoriales suficientes, siendo este un aspecto que el juez debe abordar de entrada en la valoración de los dichos del declarante. En este sentido, hay que poner atención en constatar si el testigo se encuentra, al menos, dentro de los parámetros normales de percepción, interpretación, almacenamiento y expresión de hechos, ya que, como se ha determinado desde el estudio del funcionamiento de la memoria, la sola observación de un suceso no garantiza su exacto recuerdo posterior $^{40}$. En esta perspectiva, será misión de las partes o del tribunal conseguir que el relato contenga los elementos para que el juez evalúe, por ejemplo, las capacidades visuales del testigo, o bien, para que se logre una interpretación correcta del sentido de sus palabras.

Por otra parte, se ha destacado que en el momento de la codificación del recuerdo también cumple un rol el nivel de estrés que alcanzó el declarante mientras sucedía el evento que narra, particularmente para el caso de hechos violentos, pues se ha establecido $^{41}$ que niveles muy bajos o elevados de estrés en el sujeto pueden mermar su

${ }^{38}$ Manzanero, Psicología del testimonio, cit., p. 106.

${ }^{39}$ Sobre este aspecto, debe mencionarse que los detalles sobresalientes pueden llamar tan poderosamente nuestra atención que las personas sufren una ceguera respecto del resto de elementos que se presentan en la escena, los que, por cierto, no son percibidos ni codificados como parte de su recuerdo del evento. Para un análisis de esta cuestión a partir de situaciones experimentales y cotidianas, ver: Chabris, C., y Simons, D., El gorila invisible: y otras maneras en que nuestra intuición nos engaña, traducción de Gabriela Ferrari, Siglo XXI, Buenos Aires, 2011, pp. 19 y ss. Por otra parte, se ha remarcado que igualmente influye el tipo de evento que se observa, pues no será lo mismo rememorar un homicidio que un accidente automovilístico o la suscripción de un documento, pues hay ciertos hechos cuyo impacto y rapidez impiden percibirlos y recuperarlos adecuadamente, sumado a que el rol que desempeñó el declarante en ellos también determina su recuerdo. Diges Junco, M. y Manzanero Puebla, A., "El recuerdo de los accidentes de tráfico: memoria de los testigos”, en Montoro, L., Carbonell, E., Sanmartín, J. y Tortosa, F. (editores), Seguridad vial: del factor bumano a las nuevas tecnologías, Síntesis, Madrid, 1995, p. 117. También hay que agregar que los seres humanos carecemos de herramientas biológicas para la determinación exacta de magnitudes, como la velocidad con que se mueven los objetos o la distancia a la que se encuentran, de modo que cualquier estimación que se haya ofrecido, por correcta que haya resultado en definitiva, solo constituye una evaluación azarosa que carece completamente de toda base científica. Manzanero, Memoria de testigos, cit., pp. 26 y ss.

${ }^{40}$ Manzanero, Memoria de testigos, cit., p. 23.

${ }^{41}$ Yerkes, R. y Dodson, J., "The relation of strength of stimulus to rapidity of habit-formation”, en Journal of Comparative Neurology and Psychology, Vol. 18, No 5, 1908, p. 459. 
capacidad de fijación mnemónica del suceso, mientras que situaciones moderadas facilitan la formación del recuerdo ${ }^{42}$.

\subsection{Factores que influyen en la retención del recuerdo}

Se ha advertido que durante la etapa de retención (esto es, el período que va desde la codificación del recuerdo hasta su eventual rescate desde el almacén de memoria) se puede producir el decaimiento, la modificación o la sustitución del recuerdo que se tiene respecto de un acontecimiento, debido, v. gr., al mero paso del tiempo o al influjo ejercido directa o indirectamente por terceros ${ }^{43}$. De este modo, no se puede aseverar que siempre y en todo caso una persona que ha sido testigo ocular de los hechos será capaz de proporcionar una narración que se ajuste completamente al registro original, pues es esperable que el recuerdo se deforme en mayor o menor medida mientras duerme en la memoria de largo plazo ${ }^{44}$. En este sentido, la reconfiguración del recuerdo puede llevar a que, sin ninguna intención de engañar al juez, el testigo narre un hecho que solo se corresponda vagamente con aquel que presenció directamente. De ahí que los elementos que pueden alterar el recuerdo mientras se encuentra retenido en la memoria también deben ser tenidos en cuenta al momento de asignar el mérito probatorio de lo relatado.

En este sentido, es evidente que el solo transcurso del tiempo representa un peligro inminente para la indemnidad del recuerdo ${ }^{45}$, principalmente porque, a menos que el sujeto realice ejercicios habituales de recuperación de la información que se ha agregado a su memoria, a medida que pasen los días, meses y años se irá degradando el registro que haya formado sobre un hecho, desarrollándose así el proceso de olvido. Esto consistirá en que la huella de memoria se irá borrando paulatinamente ${ }^{46}$ o que el recuerdo se situará en un lugar inaccesible debido a la pérdida de las rutas para llegar a él ${ }^{47}$ (tal como ocurre con un sendero que no es transitado por largo tiempo y que es

${ }^{42}$ Mazzoni, G., ¿Se puede creer a un testigo? El testimonio y las trampas de la memoria, traducción de José Manuel Revuelta, Trotta, Madrid, 2010, p. 44. También ver: Ibabe, cit., p. 25; Loftus, cit. , p. 33; Manzanero, Psicología del testimonio, cit., p. 114.

43 Prieto Ederra, Á., Diges Junco, M. y Bernal, M., "Investigaciones sobre la exactitud del testigo presencial", en Sobral, J. y Arce, R. (editores), La psicología social en la sala de justicia, Paidós, Barcelona, 1990 , p. 94.

${ }^{44}$ Un interesante recuento de diversas situaciones en las que queda en evidencia la alteración de los recuerdos respecto de hechos traumáticos o no, puede encontrarse en: Chabris, C., y Simons, D., cit., pp. 65 y ss.

45 Es lo que ocurre con las dificultades de prueba del hecho antiguo, donde el paso del tiempo es un enemigo real de la memoria y la percepción de los hechos. Estas dificultades aumentan cuanto más precisa sea la determinación del hecho objeto de la prueba. Hunter Ampuero, I., "Las dificultades probatorias en el proceso civil. Tratamiento doctrinal y jurisprudencial, críticas y una propuesta", en Revista de Derecho Universidad Católica del Norte, año 22, No 1, 2015, p. 216.

46 Aunque en todo caso debe apuntarse que la mayor cantidad de olvido se produce en los momentos próximos a la ocurrencia de los hechos. Manzanero, Psicología del testimonio, cit., p. 118.

47 Tulving, E. y Pearlstone, Z., "Availability versus accessibility of information in memory for words”, en Journal of Verbal Learning and Verbal Behavior, Vol. 5, N 4, 1966, p. 381. 
cubierto nuevamente por la hierba). Como ello, obviamente al sujeto le será imposible dar cuenta del hecho tal como lo había presenciado ${ }^{48}$.

Por otra parte, tratándose de testigos que se ven expuestos frecuentemente a sucesos similares, el debilitamiento del recuerdo puede generarles problemas para identificar los diferentes eventos, sea porque se genera una solapamiento entre distintos recuerdos 49 o bien porque no logran distinguir si se trata de un hecho que realmente ha ocurrido o solo es una falsa memoria ${ }^{50}$.

Ahora bien, la pérdida del recuerdo original que se guarda de un acontecimiento no solo está a merced de los efectos del olvido, que nos impide alcanzarlo nuevamente, sino también es posible que se produzca una modificación de la imagen mental que guardamos de los hechos, a raíz de la adquisición de nueva información acerca de ellos, lo que producirá una mayor afectación dependiendo, v. gr., del lapso que transcurre entre el hecho y la nueva información ${ }^{51}$, del tipo de información proporcionada ${ }^{52}$ y de la cantidad de reiteraciones a las que se ve expuesto el sujeto ${ }^{53}$. Esta situación se genera cuando el testigo recibe de otras personas versiones alternativas de los hechos, opiniones o comentarios de los mismos, mediante una conversación con ellos o por los medios de comunicación o las redes sociales, lo que ocurre particularmente en caso de eventos de connotación o relevancia pública. De esta manera, al momento de evaluar la declaración judicial se debe atender a posibles elementos que denoten la influencia de terceros, sin dejar de mencionar, lamentablemente, el rol que puede haber jugado el abogado de la parte en la preparación de las declaraciones.

\subsection{Factores que afectan la recuperación del recuerdo}

El momento en que el testigo relata los hechos destaca en las etapas anteriores del proceso mnemónico, debido a que es el único que puede ser controlado por el sentenciador, siempre y cuando se desarrolle íntegramente en su presencia (situación que tendrá lugar una vez que entre en vigencia la reforma procesal civil). Judicialmente esta etapa

${ }^{48}$ En cualquier caso, también es factible que el desvanecimiento del trazo de memoria no afecte a la totalidad del recuerdo, en el sentido que el sujeto manifieste no poseer noticias de él o no haber tenido ninguna intervención en su ocurrencia, sino que solo se generen lagunas en la información referente a los hechos. En esa situación, es perfectamente posible que los vacíos afecten únicamente a los aspectos accesorios del suceso, lo que no debería aminorar el mérito de convicción que se asigne al medio de prueba.

49 Manzanero, Psicología del testimonio, cit., p. 84.

${ }^{50}$ Diges Junco, M., Los falsos recuerdos: sugestión y memoria, Paidós, Barcelona, 1997, pp. 17 y ss.

${ }^{51}$ Loftus, E., Miller, D. y Burns, H., "Semantic integration of verbal information into a visual memory", en Journal of Experimental Psychology: Human Learning and Memory, Vol. 4, No 1, 1978, p. 23. Sobre el mismo aspecto, pero con una mirada diferente, ver: Manzanero Puebla, A., “¿Son realmente diferentes los relatos sobre un hecho real y los sugeridos?”, en Anuario de Psicología Jurídica, No 14, 2004, p. 115.

52 Hall, D., Loftus, E. y Tousignant, J., "Postevent information and changes in recollection for a natural event”, en Wells, G. y Loftus, E. (editores), Eyewitness testimony: psychological perspectives, Cambridge University Press, Cambridge, 1984, p. 135.

${ }^{53}$ Manzanero, Memoria de testigos, cit., p. 75. 
se inicia con la toma de juramento al testigo y sigue con la formulación de preguntas por parte de los abogados y del juez presente, con el fin de que el declarante dé cuenta de los hechos respecto de los que ha sido llamado a declarar ante el tribunal. Se espera, por tanto, que el sujeto rescate desde el baúl de los recuerdos (nunca mejor dicho) la huella que en su momento dejó en su memoria la experiencia sensible que ahora debe describir, lo que solo se podrá realizar exitosamente cuando las etapas de codificación y retención hayan tenido lugar sin inconvenientes ni errores que afecten gravemente el recuerdo.

Partiendo de la base que la percepción de los hechos ha sido de buena calidad, que la información ha estado almacenada solo un tiempo breve y que no ha tenido lugar ninguna influencia interna o externa que haya reformado sustancialmente el recuerdo ${ }^{54}$, el testigo estará situado en perfecta posición para responder a los requerimientos de información que se le hagan respecto de los hechos, aunque para ello será trascendental la forma en que se le solicita dicha información, pues la memoria tendrá un mejor funcionamiento cuando se le haga operar bajo ciertas condiciones.

En este sentido, los estudios indican que lo primero que se debe hacer es solicitar al testigo que se reinstale mentalmente en el contexto en que se encontraba en el momento en que percibió los hechos ${ }^{55}$, pues de esa forma se mejora la conexión entre la codificación y la recuperación de las memorias creadas. A ello se suma la manera en que el sujeto cuenta el recuerdo que tiene alojado en su memoria, ya que se ha destacado que la narración libre permitiría cautelar la indemnidad del recuerdo en mayor medida que la declaración obtenida mediante un interrogatorio ${ }^{56}$.

Además, durante la práctica de las pruebas hay que poner atención -siguiendo las palabras de Carnelutti- en la cualidad de la persona que escuch $a^{57}$, es decir, en aquel que solicita o recibe el testimonio, pues con la influencia que puede ejercer en el declarante puede propiciar o desincentivar la narración de un recuerdo alterado o no verdadero. Esto debe vincularse necesariamente con dos cuestiones que dependen directamente del nivel de conocimiento que tiene de los hechos la persona que solicita o recibe el testimonio. En este sentido, si el entrevistado entiende o percibe que el destinatario del relato tiene un conocimiento de los hechos al menos equivalente al propio, esto puede producir dos efectos: por una parte, disuadirlo o llevarlo a poner en tela de juicio cualquier intención mendaz que pueda pretender concretar en el acto de la declaración; y por otra, la confluencia de un requirente que conoce perfectamente los hechos con un sistema de interrogatorio directo aumenta exponencialmente las posibilidades de implantar falsos recuerdos en el deponente o, en el escenario menos perjudicial, alterar o modificar los existentes. Así, un testigo que internamente tenga la convicción que su recuerdo está debilitado o

\footnotetext{
${ }^{54}$ Ibabe, cit., p. 19.

${ }^{55}$ En esta perspectiva, el principio de codificación específica propone que la recuperación exitosa solo podrá conseguirse si se realiza teniendo en cuenta la forma en que se llevó a cabo el almacenamiento de la información. Acerca de este principio, ver: Tulving, E. y Thomson, D., "Encoding specificity and retrieval processes in episodic memory", en Psychological Review, Vol. 80, N 5, 1973, p. 359.

${ }^{56}$ Diges y Alonso-Quecuty, cit., p. 15. También: Manzanero, Psicología del testimonio, cit., p. 137. .

${ }^{57}$ Carnelutti, cit., p. 151.
} 
que posee lagunas puede ser impresionado fácilmente por un interrogador que aparente o demuestre tener un conocimiento cabal de los eventos que pregunta, de modo que, suponiendo que el abogado o juez sabe más que él concerniente a los hechos, podrá ser más susceptible a la información que pueda entregársele por medio de las preguntas ${ }^{58}$. En este mismo aspecto, también es posible que el testigo se vea impresionado por el entorno en que se lleva a cabo la declaración judicial, por la importancia de la misma, por el estatus de quienes toman parte del proceso o por la forma en que se dirigen a él, lo que puede llevar a la afectación del contenido de su declaración.

\section{El SISTEMA DE VALORACIÓN DEL TESTIMONIO EN EL PCPC}

De la sola lectura del articulado del PCPC se puede establecer que el legislador no ha previsto una norma específica que se refiera a la forma en que debe valorarse el resultado de la prueba testimonial, ante ello se hace necesario aplicar la regulación general contenida en el artículo 295 59 . De esta manera, la determinación del mérito de convicción de las declaraciones testificales debe hacerse aplicando el sistema de la sana crítica, lo que, como se sabe, representa una completa modificación respecto de la regulación procesal civil vigente que se refiere a la materia. En efecto, el artículo 384 del Código de Procedimiento Civil constituye una norma que se considera el paradigma de la prueba tasada, pues el legislador, situándose en varios supuestos, señala en qué casos se debe o no dar por cierto lo que han dicho los testigos, sin interesarse para nada en el nivel de convicción subjetiva que el sentenciador ha podido formarse racionalmente respecto de las declaraciones de cada uno de ellos, ni en la conclusiones que ha podido elaborar al efecto ${ }^{60}$.

La decisión del legislador de desprenderse de la tarea de valorar apriorísticamente las declaraciones y confiarle el desarrollo de esta labor al juez de la causa, es uno más de los aspectos en los que se sigue la línea de lo establecido en las reformas procesales que ya han sido puestas en marcha ${ }^{61}$, de modo que no constituye mayor novedad en el sistema de enjuiciamiento chileno. Por consiguiente, se puede afirmar que, como ocurre en sede penal, laboral y de familia, en el nuevo procedimiento civil radicará única y exclusivamente en el sentenciador el deber de salir en búsqueda de los elementos que

\footnotetext{
${ }^{58}$ Smith, V. y Ellsworth, P., "The social psychology of eyewitness accuracy: misleading questions and communicator expertise", en Journal of Applied Psychology, Vol. 72, No 2, 1987, p. 294.

${ }^{59}$ Artículo 295.- Valoración de la prueba. Salvo que la ley atribuya un valor determinado a un medio probatorio, el juez apreciará la prueba de acuerdo a las reglas de la sana crítica. En consecuencia, deberá estarse a los principios de la lógica, las máximas de la experiencia y los conocimientos científicamente afianzados, salvo texto legal que expresamente contemple una regla de apreciación diversa.

Sin embargo, el acto o contrato solemne solo puede ser acreditado por medio de la solemnidad prevista por el legislador.

${ }^{60}$ Bordalí, Cortez y Palomo, cit., p. 345. También: Figueroa y Morgado, cit., p. 211; Casarino Viterbo, M., Manual de derecho procesal, Tomo IV, Sexta edición, Editorial Jurídica de Chile, Santiago, p. 86.

${ }^{61}$ Así se establece en los artículos 297 del Código Procesal Penal, 32 de la Ley de Tribunales de Familia y 456 del Código del Trabajo.
} 
le permitan valorar acertadamente las declaraciones de los testigos presentados por las partes en un litigio particular. Una tarea de esta magnitud puede convertirse en una carga demasiado pesada para el juez, por lo que siempre puede venirle bien que el legislador al menos prevea algunos lineamientos generales para valorar las declaraciones, lo que tiene lugar, por ejemplo, cuando en diversos ordenamientos procesales se menciona que el declarante debe expresar la razón de ciencia de sus dichos, lo que equivale a explicar cuál es la fuente de la que extrae su conocimiento de los hechos y asimismo cuáles fueron las circunstancias de tiempo, modo y lugar en que ellos tuvieron lugar ${ }^{62}$, información que siempre resulta de utilidad para el juez que está llamado a fijar el peso de este medio de prueba.

Pero más allá de la consideración de elementos, si se quiere, secundarios dentro del ejercicio valorativo, lo importante es que el juzgador no pase por alto que debe analizar primeramente la veracidad de la declaración para luego hacer lo propio con su exactitud, pues ese es el único procedimiento general que le permitirá obtener conclusiones racionales y fundadas acerca del mérito de convicción de los relatos. Siendo esta una cuestión tan trascendental para que la sana crítica pueda llenarse de contenido y materializar todas las ventajas que acarrea para el juicio jurisdiccional, es deseable que el legislador procesal contemple una clara referencia a ambos aspectos en las normas que regulen la apreciación de estos medios de convicción. Sin embargo, esto no ocurre con la regulación contenida en el PCPC, pues siendo innegable que se advierte una clara mención a la honestidad de los declarantes como uno de los aspectos fundamentales de la valoración, nada se dice respecto de la precisión de los relatos y su adecuación con la forma en que ocurrieron los hechos, aspecto que se puede ver afectado por las deficiencias que puedan provenir de la memoria de los testigos.

Así, sin que de ninguna manera se entienda que se está sugiriendo el establecimiento de pautas obligatorias para la valoración de los relatos que se impongan al sentenciador del caso particular, el legislador debe avanzar hacia el señalamiento de ciertos criterios generales que, sin ser taxativos ni vinculantes, sirvan para facilitar la tarea del juez tanto en lo que respecta al análisis teórico de la honestidad y exactitud de las declaraciones como para la subsecuente plasmación de su mérito en el texto de la sentencia. En este sentido, partiendo de la prevención de que no existe ningún indicador absoluto de mendacidad ni de certeza total de lo expresado en un relato fáctico, es menester considerar

${ }^{62}$ Esto es lo que ocurre, por ejemplo, en el Código General del Proceso de Colombia, artículo 221: 3. El juez pondrá especial empeño en que el testimonio sea exacto y completo, para lo cual exigirá al testigo que exponga la razón de la ciencia de su dicho, con explicación de las circunstancias de tiempo, modo y lugar en que haya ocurrido cada becho y de la forma como llegó a su conocimiento (...). También en la Ley de Enjuiciamiento Civil española (art. 310) se dispone que 3. En cada una de sus respuestas, el testigo expresará la razón de ciencia de lo que diga. A su vez, el artículo 151 del Código Procesal Civil Modelo para Iberoamérica contempla que (e)l Tribunal exigirá al testigo que exponga la razón de la ciencia de sus dichos, con explicación de las circunstancias de tiempo, modo y lugar en que haya ocurrido cada becho y de la forma como llegó a su conocimiento. Por su parte, en un sentido similar, el PCPC establece en el artículo 318 inciso $2^{\circ}$ que: Todo testigo dará razón circunstanciada de los hechos sobre los cuales declarare, expresando si los hubiere presenciado, si los dedujere de antecedentes que le fueren conocidos o si los bubiere oído referir a otras personas. 
que los estudios científicos sobre el particular han determinado que la valoración de las deposiciones solo podrá calificarse de objetiva y racional cuando se sustente, al menos, en el análisis de su nivel de contextualización, concordancia interna, coherencia externa, calidad del recuerdo y de ciertas condiciones personales del deponente que coadyuvan en la interpretación correcta de sus dichos ${ }^{63}$. De esta forma, el legislador procesal civil podría indicar que el juez deberá valorar las declaraciones testimoniales atendiendo al grado de veracidad y exactitud de los relatos, para ello tendrá en cuenta su contextualización, concordancia, relación con otras pruebas del proceso, calidad de la memoria del declarante respecto de los hechos que relata o cualquier otra circunstancia que en consideración del juez pueda ser empleada para determinar racionalmente el mérito de este medio de prueba ${ }^{64}$.

\section{ACERCA DEL DEBER DE DECIR LA VERDAD}

El texto del PCPC es claro: los testigos tienen el deber de decir la verdad concerniente a lo que se les preguntare ${ }^{65}$. Con ello se quiere resaltar que todo declarante está sometido a la obligación de abstenerse de mentir en el juicio -mentira como oposición a la verdad a que se refiere la norma citada-, cuestión que por lo demás se le podrá hacer presente expresamente al comienzo del acto de su deposición. En este aspecto, justo después que

${ }^{63}$ Para un estudio más detallado de los criterios de valoración de la prueba testimonial, ver: Nieva, cit., p. 222. También: Contreras, cit., pp. 275 y ss.

${ }^{64}$ En particular hay que señalar que los sistemas procesales comparados, en términos generales, solo se refieren a elementos que buscan alertar al juez respecto de una falta de honestidad del declarante, regulación que puede calificarse de insuficiente a partir de lo expresado en este trabajo. Así, es posible detectar que los legisladores procesales del entorno, junto con hacer referencias a las razones de ciencia (ver supra nota 62), se limitan a establecer una regulación de la institución de las tachas. Acerca de este aspecto puede mencionarse, a modo ejemplar, lo previsto por el artículo 211 del Código General del Proceso de Colombia, que establece que: Cualquiera de las partes podrá tachar el testimonio de las personas que se encuentren en circunstancias que afecten su credibilidad o imparcialidad, en razón de parentesco, dependencias, sentimientos o interés en relación con las partes o sus apoderados, antecedentes personales u otras causas. Lo propio ocurre con la Ley de Enjuiciamiento Civil española (artículo 376) y el Código General del Proceso uruguayo (artículo 158). En todo caso, hay que remarcar que el artículo 215 del Código Federal de Procedimientos Civiles de México constituye una notable excepción al panorama regional en lo que se refiere al señalamiento de criterios de valoración de la prueba testimonial por parte del legislador. De esta forma, si bien esta disposición confía la determinación del mérito de la prueba testimonial al prudente arbitrio del sentenciador, al mismo tiempo proporciona algunos elementos que deben ser considerados por él al momento de desarrollar esta tarea. Por ejemplo, indica que el juez debe tener en cuenta (q)ue los testigos convengan en lo esencial del acto que refieran, aun cuando difieran en los accidentes o (q) ue la declaración sea clara, precisa, sin dudas ni reticencias, sobre la substancia del hecho y sus circunstancias esenciales. De ahí que, junto con lo propuesto supra y las adecuaciones que sean pertinentes, esta norma puede servir de guía para la construcción de una disposición que se haga cargo de esta cuestión en el marco de la reforma procesal civil nacional.

${ }^{65}$ Artículo 310.- Deberes del testigo. Toda persona que no se encontrare legalmente exceptuada tendrá la obligación de concurrir al llamamiento judicial practicado y prestar declaración testimonial. Tendrá, igualmente, el deber de decir la verdad sobre lo que se le preguntare y de no ocultar hechos, circunstancias o elementos acerca del contenido de su declaración. 
se le haya tomado juramento o promesa -solemnidad que, por cierto, debe entenderse como un refuerzo o acicate para la satisfacción del deber de honestidad-se otorga al juez la posibilidad de explicar al testigo el sentido de su obligación de ser veraz ${ }^{66}$. Así, es evidente que la regulación legal pone por delante el temor de que los testigos mientan en cada una de sus declaraciones, desconfianza que acompaña a este tipo de pruebas desde su aparición en la escena judicial ${ }^{67}$, pero que no ha evitado su utilización en todo tipo de procedimientos, principalmente debido a que los testigos siempre constituyen una -o incluso la única- fuente de información disponible con la que es posible contrastar las alegaciones formuladas por los litigantes ${ }^{68}$. En todo caso, la sospecha patente acerca de la deslealtad de los declarantes es lo que lleva a que el legislador procesal fomente el deber de veracidad, descuidando toda referencia a sus capacidades mnemónicas o a la indemnidad de los recuerdos que almacenan en su memoria.

En esa perspectiva, será posible entender que se ha configurado un incumplimiento del deber general de veracidad impuesto a los testigos cuando estos han proporcionado una declaración falsa, vale decir, un relato que carece de correspondencia con la realidad o verdad de lo sucedido, pero ¿qué pasa si el testigo se ajusta estrictamente al recuerdo que almacena en su memoria y es dicho recuerdo el que difiere de la realidad? En este sentido, como se ha apuntado supra, se torna necesario precisar en primer término si esa disparidad se ha gestado a partir de la voluntad clara y directa del declarante, o bien solo es fruto de una memoria deficiente o alterada, caso en el que debemos entender que el testigo está dando plena satisfacción al deber que se le ha impuesto y al juramento que ha debido prestar. En este último caso, la exposición de los hechos corresponde a su propia y particular versión verdadera de lo sucedido ${ }^{69}$, básicamente porque, parafraseando la primera acepción del vocablo verdad que nos entrega el Diccionario de la RAE, existe una conformidad entre los hechos y la imagen que de ellos se ha formado la mente del declarante.

Desde luego, es menester mencionar que la determinación de aquello que constituye una declaración falsa dependerá del concepto de verdad con el que se trabaje y de las pretensiones que se manifiesten al respecto, aspecto en que también intervienen las herramientas disponibles para alcanzar esa verdad. De esta manera, sin ánimo de entrar en cuestiones de índole filosófica o religiosa -que por lo demás salen del ámbito de este trabajo-, la verdad que es posible descubrir en un proceso judicial determinado tiene directa relación con las características y configuración particular de ese proceso,

\footnotetext{
${ }^{66}$ Artículo 316 inc. $3^{\circ} \mathrm{El} \mathrm{juez,} \mathrm{si} \mathrm{lo} \mathrm{estimare} \mathrm{necesario,} \mathrm{instruirá} \mathrm{al} \mathrm{testigo} \mathrm{acerca} \mathrm{del} \mathrm{sentido} \mathrm{del} \mathrm{juramento} \mathrm{o}$ promesa y de su obligación de ser veraz, así como de las penas con las cuales la ley castiga el delito de falso testimonio.

${ }^{67}$ Acerca de la desconfianza que este medio de prueba ha suscitado desde tiempos antiguos, ver: Silva Melero, V., La prueba procesal, Tomo I, Editorial Revista de Derecho Privado, Madrid, 1963, pp. 205 y 206.

${ }^{68}$ Devis Echandía indica que la utilización de la prueba testimonial en el proceso judicial responde a una necesidad teórica y práctica, generada a raíz de que no se dispone de otros medios de convicción. Devis, cit., Tomo II, p. 79.

${ }^{69}$ En el mismo sentido, se ha apuntado que los sujetos que entregan un testimonio basado en falsos recuerdos están convencidos de que aquello ocurrió, equivaliendo su recuerdo en calidad al de un testimonio verdadero, Köhnken, Manzanero y Scott, cit., p. 15. En relación con las falsas memorias, ver: Volbert y Steller, cit., p. 208.
} 
los recursos disponibles y los medios de prueba específicos que se hayan aportado válidamente y que estén a disposición del sentenciador para adoptar su decisión, razón por la que se ha afirmado que en el proceso judicial se trabaja con una versión relativa y contextualizada de la verdad ${ }^{70}$. Dicho de otra forma, la verdad de los hechos para el juez será aquella que pueda reconstruir empleando los medios de convicción que tenga disponibles para contrastar las alegaciones fácticas de las partes, para así determinar cómo ocurrieron los acontecimientos sujetos a verificación.

Ahora bien, para que el proceso de confirmación de la verdad fáctica resulte exitoso, se requiere de elementos - conclusiones probatorias-idóneos para fiscalizar si los hechos han sucedido como se relata en las versiones que han entregado las distintas partes del juicio, razón por la que estos elementos deben comenzar por contar con un sello de calidad acerca de su propia veracidad. De ahí que sea imprescindible que cada uno de los medios de prueba específicos que son empleados por el juez para fundar su decisión -y, por cierto, la declaración de cada uno de los testigos- dé cuenta de cómo han acaecido realmente los sucesos, pues solo en ese caso podrán emplearse como parámetros de control de lo expuesto por los litigantes. Así las cosas, teniendo siempre presente que las certezas absolutas se sitúan en un plano inalcanzable para el proceso judicial y sus intervinientes ${ }^{71}$, el problema estará en fijar el estándar o umbral de veracidad mínimo que se le exigirá a las declaraciones testificales, siendo luego misión del juzgador decidir si un relato específico puede estimarse veraz y, en consecuencia, emplearse como herramienta de control fáctico.

En esa perspectiva, teniendo presente que el juez debe llevar a cabo la reconstrucción de lo sucedido exclusivamente a base de los materiales que se hayan incorporado válidamente al proceso, de modo que la verdad para ese caso será la que dichos medios permitan alcanzar mediante el empleo de la lógica y la razón del sentenciador, la decisión de la idoneidad de la declaración deberá tomarse en atención a los elementos que pueden detectarse en el contenido del relato y en las conclusiones que se desprendan de un análisis holístico del acervo probatorio con que cuenta el proceso. Así, no puede pretenderse la fijación del nivel de veracidad de lo relatado por un testigo mediante la utilización de consideraciones ajenas al proceso ni en atención a cuestiones que contravengan la racionalidad. Además, tampoco puede aspirarse a contar con conclusiones que se consigan luego de pasar las declaraciones por un tamiz absoluto de veracidad, pues usualmente nos enfrentamos a la imposibilidad de contar con él, y por lo demás, en el caso en que efectivamente existiera dicha fuente para el conocimiento de la real ocurrencia de los hechos y ella estuviera a disposición del juzgador, la declaración de los testigos y el ejercicio valorativo respectivo se tornarían completamente inútiles.

${ }^{70}$ Taruffo, M., La prueba de los hechos, traducción de Jordi Ferrer Beltrán, Segunda edición, Editorial Trotta, Madrid, 2005, p. 75.

${ }^{71}$ En este sentido, Calamandrei apuntaba que el proceso es un método de conocimiento de la verdad, pero no de las verdades últimas y supremas que escapan a los hombres pequeños, sino la verdad bumilde y diaria (...). Calamandrei, P., "Proceso y justicia", en Derecho procesal civil, traducción de Santiago Sentís Melendo, Ediciones Jurídicas Europa-América, Buenos Aires, 1986, p. 215. 


\section{COROLARIO: EL OLVIDO DE LA MEMORIA}

La vinculación que el PCPC establece entre la declaración de testigos y la verdad no es nueva. De hecho, ya en las Partidas se señalaba que el juez debía creer los dichos de aquellos testigos que entendiere que dicen la verdat ó que se acercan mas á ella $(\ldots)^{72}$. No obstante, el desarrollo de los conocimientos en psicología del testimonio en las últimas décadas exige o demanda completar el ejercicio judicial que se desarrolla respecto del contenido del material fáctico que los testigos proveen al proceso.

De esa forma, si bien la prohibición de la mentira y, por consiguiente, la adquisición de la verdad de parte de los declarantes en el proceso debe ser siempre el primer objetivo perseguido por el sistema, parece necesario que esta ambición sea puesta en contexto y que se acepte expresamente que, de forma independiente a la mayor o menor rectitud de los deponentes, la descripción verbal de los hechos que realizan los sujetos llamados ante el tribunal está afecta a ciertas limitaciones, aspecto del que el legislador procesal civil ha guardado absoluto silencio. En este sentido, se debe partir por reconocer que la memoria de las personas no es exacta. Por el contrario, ella es esencialmente falible, de manera que la determinación del nivel de calidad del recuerdo debe ocupar un lugar central en la tarea valorativa del sentenciador.

Es evidente que la declaración judicial se integra tanto de un componente volitivo como de uno mnemónico, por lo que si bien el testigo siempre puede decidir activamente qué y cuánta información revelar ${ }^{73}$, esta decisión se tomará sobre la base del recuerdo efectivo que almacene de los hechos. De ahí que más que instar al testigo para que declare la verdad de los eventos que motivan el conflicto judicial, el legislador debe reconocer expresamente que tanto la exactitud del recuerdo como la lealtad del declarante son los dos grandes elementos que el juez debe sopesar para determinar el valor de lo relatado. Por tanto, junto con que la legislación positiva imponga derechamente al testigo el deber de relatar los hechos tal como los recuerda, es imprescindible que ella dé cuenta de los elementos esenciales de los que el sentenciador debe servirse para llevar a cabo su tarea valorativa (v. gr., contextualización del relato, calidad del recuerdo, coherencia). Ellos permiten construir un sustento racional para la fijación del peso de las deposiciones, a la vez que recuerdan al juez que solo habrá posibilidades de apreciar correctamente la narración cuando se analice la honestidad del declarante, la calidad de su recuerdo y la precisión de su relato. Con esos lineamientos generales, sin limitar en caso alguno el ámbito de acción que el modelo de sana crítica reconoce al juez, se podrán obtener conclusiones probatorias de mejor calidad, no solo porque atenderán a todos los elementos que sirven para determinar objetivamente la calidad de los relatos, sino también porque las razones que se han tenido en cuenta para fijar su mérito probatorio podrán ser expresadas de forma más clara y precisa.

\footnotetext{
72 Partida III, Título XVI, Ley XLI.

73 Volbert y Steller, cit., p. 213.
} 


\section{BIBLIOGRAFÍA}

Abel Lluch, X., "Configuración de las reglas de la sana crítica en la Ley 1/2000, de Enjuiciamiento Civil", en Revista Vasca de Derecho Procesal y Arbitraje, Vol. XXV, No 2, 2013.

Alvarado Velloso, A., La prueba judicial: reflexiones críticas sobre la confirmación procesal, Tirant lo Blanch, Valencia, 2006.

ArCE, R. y Fariña, F., "Peritación psicológica de la credibilidad del testimonio, la huella psíquica y la simulación: el Sistema de Evaluación Global (SEG)”, en Papeles del Psicólogo, No 92, 2005.

Benfeld, J., "Los orígenes del concepto de 'sana crítica”, en Revista de Estudios Histórico-Jurídicos, $\mathrm{N}^{\circ} 35,2013$.

Bordalí, A., Cortez, G. y Palomo, D., Proceso civil: El juicio ordinario de mayor cuantía, procedimiento sumario y tutela cautelar, Segunda edición, Thomson Reuters-La Ley, Santiago, 2014.

Calamandrei, P., "Proceso y justicia", en Derecho procesal civil, traducción de Santiago Sentís Melendo, Ediciones Jurídicas Europa-América, Buenos Aires, 1986.

Carnelutti, F., La prueba civil, traducción de Niceto Alcalá-Zamora y Castillo, Segunda edición, Ediciones Depalma, Buenos Aires, 1982.

Carocca Pérez, A., Manual de derecho procesal: Los procesos declarativos, Tomo II, LexisNexis, Santiago, 2003.

Casarino Viterbo, M., Manual de derecho procesal, Tomo IV, Sexta edición, Editorial Jurídica de Chile, Santiago.

Chabris, C., y Simons, D., El gorila invisible: y otras maneras en que nuestra intuición nos engaña, traducción de Gabriela Ferrari, Siglo XXI, Buenos Aires, 2011.

Coloma Correa, R., “¿Realmente importa la sana crítica?”, en Revista Chilena de Derecho, Vol. 39, $\mathrm{N}^{\mathrm{o}} 3,2012$.

Coloma Correa, R. y Agüero San Juan, C., "Lógica, ciencia y experiencia en la valoración de la prueba”, en Revista Chilena de Derecho, Vol. 41, No 2, 2014.

Contreras Rojas, C., La valoración de la prueba de interrogatorio, Marcial Pons, Madrid, 2015.

Devis Echandía, H., Teoría general de la prueba judicial, Quinta edición, Temis, Bogotá, 2002.

Diges Junco, M., Los falsos recuerdos: sugestión y memoria, Paidós, Barcelona, 1997.

Diges Junco, M. y Alonso-Quecuty, M., Psicología forense experimental, Promolibro, Valencia, 1993.

Diges Junco, M. y Manzanero Puebla, A., "El recuerdo de los accidentes de tráfico: memoria de los testigos”, en Montoro, L., Carbonell, E., Sanmartín, J. y Tortosa, F. (editores), Seguridad vial: del factor humano a las nuevas tecnologías, Síntesis, Madrid, 1995.

Ekman, P., Cómo detectar mentiras: una guía para utilizar en el trabajo, la política y la pareja, Paidós, Barcelona, 2009.

Figueroa Yávar, J. y Morgado San Martín, E., Procedimientos civiles e incidentes, LegalPublishing, Santiago, 2013.

Gamer, M., "Mind reading using neuroimaging. Is this the future of deception detection?", en European Psychologist, Vol. 19, No 3, 2014.

Godoy-Cervera, V. e Higueras, L., "El análisis de contenido basado en criterios (CBCA) en la evaluación de la credibilidad del testimonio", en Papeles del Psicólogo, Vol. 26, 2005.

Gómez Orbaneja, E., Derecho procesal civil, Vol. I, Octava edición, Madrid, 1979.

GonZÁlez Castillo, J., "La fundamentación de las sentencias y la sana crítica”, en Revista Chilena de Derecho, Vol. 33, No 1, 2006.

Gorphe, F., La crítica del testimonio, traducción de Mariano Ruiz-Funes, Sexta edición, Reus, Madrid, 1980. 
Hall, D., Loftus, E. y Tousignant, J., "Postevent information and changes in recollection for a natural event", en Wells, G. y Loftus, E. (editores), Eyewitness testimony: psychological perspectives, Cambridge University Press, Cambridge, 1984.

Hunter Ampuero, I., "Las dificultades probatorias en el proceso civil. Tratamiento doctrinal y jurisprudencial, críticas y una propuesta”, en Revista de Derecho Universidad Católica del Norte, año 22, $\mathrm{N}^{\circ} 1,2015$.

Iвabe Erostarbe, I., Psicología del testimonio, Erein, Donostia, 2000.

Köhnken, G., Manzanero, A., y Scott, M. T., "Análisis de la validez de las declaraciones: mitos y limitaciones”, en Anuario de Psicología Jurídica, Vol. 25, 2015.

Loftus, E., Greene, E. y Doyle, J., "La psicología del testimonio del testigo presencial", en Raskin, D. (editor), Métodos psicológicos en la investigación y pruebas criminales, traducción de Susana Gorbeña Etxebarría, Desclée de Brouwer, Bilbao, 1994.

Loftus, E., Miller, D. y Burns, H., "Semantic integration of verbal information into a visual memory”, en Journal of Experimental Psychology: Human Learning and Memory, Vol. 4, No 1, 1978.

Loftus, E., Schooler, J., Boone, S. y Kline, D., "Time went by so slowly: overestimation of event duration by males and females”, en Applied Cognitive Psychology, Vol. 1, No 1, 1987.

Manzanero Puebla, A., "¿Son realmente diferentes los relatos sobre un hecho real y los sugeridos?”, en Anuario de Psicología Jurídica, No 14, 2004.

Psicología del testimonio, Ediciones Pirámide, Madrid, 2008.

, Memoria de testigos, Ediciones Pirámide, Madrid, 2010.

Mazzoni, G., ¿Se puede creer a un testigo? El testimonio y las trampas de la memoria, traducción de José Manuel Revuelta, Trotta, Madrid, 2010.

Montero Aroca, J., La prueba en el proceso civil, Séptima edición, Civitas Thomson Reuters, Cizur Menor, 2012.

Nieva Fenoll, J., La valoración de la prueba, Marcial Pons, Madrid, 2010.

Prieto Ederra, Á., Diges Junco, M. y Bernal, M., "Investigaciones sobre la exactitud del testigo presencial”, en Sobral, J. y Arce, R. (editores), La psicología social en la sala de justicia, Paidós, Barcelona, 1990.

Prieto-Castro y Ferrándiz, L., Manual de derecho procesal civil, Tomo I, Universidad de Madrid. Facultad de Derecho. Sección de publicaciones e intercambio, Madrid, 1962.

Rodríguez Papic, I., Procedimiento civil: Juicio ordinario de mayor cuantía, Séptima Edición, Editorial Jurídica de Chile, Santiago.

SancinetTi, M., "Testimonio único y principio de la duda", en InDret, $\mathrm{N}^{\circ}$ 3, 2013.

Silva Melero, V., La prueba procesal, Tomo I, Editorial Revista de Derecho Privado, Madrid, 1963.

SMITH, V. y Ellsworth, P., "The social psychology of eyewitness accuracy: misleading questions and communicator expertise", en Journal of Applied Psychology, Vol. 72, $\mathrm{N}^{\circ} 2,1987$.

SPORER, S., "The less travelled road to truth: verbal cues in deception detection in accounts of fabricated and self-experienced events”, en Applied Cognitive Psychology, Vol. 11, No 5, 1997.

Steller, M., "Recent developments in statement analysis", en Yuille, J. C. (editor), Credibility assessment, Springer, Deventer, Vol. 47, 1989.

Steller, M. y Köhnken, G., “Análisis de declaraciones basado en criterios”, en Raskin, D. (editor), Métodos psicológicos en la investigación y pruebas criminales, Springer, Bilbao, 1994.

TARuffo, M., La prueba de los hechos, traducción de Jordi Ferrer Beltrán, Segunda edición, Editorial Trotta, Madrid, 2005.

, La prueba, traducción de Laura Manríquez y Jordi Ferrer Beltrán, Marcial Pons, Madrid, 2008.

Simplemente la verdad: el juez y la construcción de los hechos, traducción de Daniela Accatino Scagliotti, Marcial Pons, Madrid, 2010. 
Tulving, E. y Pearlstone, Z., "Availability versus accessibility of information in memory for words”, en Journal of Verbal Learning and Verbal Behavior, Vol. 5, N 4, 1966.

Tulving, E. y Thomson, D., "Encoding specificity and retrieval processes in episodic memory", en Psychological Review, Vol. 80, No 5, 1973.

Undeutsch, U., "Statement reality analysis", en Trankell, A. (editor), Reconstructing the past: the role of psychologists in criminal trials, p. A. Norstedt, Estocolomo, 1982.

Volbert, R. y Steller, M., "Is this testimony truthful, fabricated, or based on false memory? Credibility assessment 25 years after Steller and Köhnken (1989)”, en European Psychologist, Vol. 19, No 3, 2014.

VRIJ, A., "Criteria-based content analysis: a qualitative review of the first 37 studies", en Psychology, Public Policy, and Law, Vol. 11, No 1, 2005.

Detecting lies and deceit: Pitfalls and opportunities, Segunda edición, Wiley, Chichester, 2008.

, "Interviewing to detect deception", en European Psychologist, Vol. 19, No 3, 2014.

WeLLs, G., "Applied eyewitness-testimony research: system variables and estimator variables", en Journal of Personality and Social Psychology, Vol. 36, $\mathrm{N}^{\circ}$ 12, 1978.

Yerkes, R. y Dodson, J., "The relation of strength of stimulus to rapidity of habit-formation", en Journal of Comparative Neurology and Psychology, Vol. 18, No 5, 1908.

Zuckerman, M., Depaulo, B. y Rosenthal, R., "Verbal and nonverbal communication of deception”, en Advances in Experimental Social Psychology, Vol. 14, 1981. 